\title{
Prenatal Stress and Risk of Febrile Seizures in Children: A Nationwide Longitudinal Study in Denmark
}

\author{
Jiong Li · Jørn Olsen · Carsten Obel · Jakob Christensen · \\ Dorthe Hansen Precht • Mogens Vestergaard
}

Published online: 17 March 2009

(C) The Author(s) 2009. This article is published with open access at Springerlink.com

\begin{abstract}
We aimed to examine whether exposure to prenatal stress following maternal bereavement is associated with an increased risk of febrile seizures. In a longitudinal population-based cohort study, we followed $1,431,175$ children born in Denmark. A total of 34,777 children were born to women who lost a close relative during pregnancy or within 1 year before the pregnancy and they were included in the exposed group. The exposed children had a risk of febrile seizures similar to that of the unexposed children (hazard ratio (HR) 1.00, 95\% CI 0.94 1.06). The HRs did not differ according to the nature or timing of bereavement. Our data do not suggest any causal link between exposure to prenatal stress and febrile seizures in childhood.
\end{abstract}

J. Li $(\bowtie) \cdot$ J. Olsen

The Danish Epidemiology Science Centre, Department of Epidemiology, Institute of Public Health, The University of Aarhus, Vennelyst Boulevard 6, 8000 Århus C, Denmark e-mail: j1@soci.au.dk

J. Olsen

Department of Epidemiology, School of Public Health,

University of California, Los Angeles, CA, USA

C. Obel $\cdot$ M. Vestergaard

Department of General Practice, Institute of Public Health, University of Aarhus, Århus, Denmark

J. Christensen

Department of Neurology, Aarhus University Hospital,

Århus, Denmark

D. H. Precht

Pediatric Department, Holbaek University Hospital, Holbaek, Region Zealand, Denmark
Keywords Prenatal stress - Bereavement .

Febrile seizures · Fetal programming - Longitudinal study

\section{Introduction}

Febrile seizures is the most common type of seizure in childhood, affecting 2-5\% of all children between 3 months and 5 years of age (Forsgren et al. 1990; Hauser 1994). It is believed that both genetic and early environmental factors play a role in the etiology of the disease (Berkovic and Scheffer 1998; Vestergaard et al. 2002), and several studies suggested that prenatal factors may influence the risk of febrile seizures (Cassano et al. 1990; Greenwood et al. 1998; Nelson and Ellenberg 1990; Vestergaard et al. 2002, 2005).

Mounting evidence indicates that prenatal stress can have programming effects on brain development (Seckl and Holmes 2007; Van den Bergh et al. 2005; Welberg and Seckl 2001), which may underlie the link between prenatal factors and some neurological disorders in childhood. Stress hormones, such as glucocorticoids and corticotrophinreleasing hormone $(\mathrm{CRH})$, are related to alterations in the fetal central nervous systems (Seckl 2004; Wadhwa 2005; Weinstock 2005). Both endogenous and synthetic glucocorticoid exposure may modify the neurotransmitter systems and transcriptional machinery with impact on brain morphology (Barrot et al. 2001; Kapoor et al. 2006). Some studies have shown that severe stress may cause structural changes the hippocampus and decrease the seizure threshold (Edwards et al. 2002; Brunson et al. 2003; Vishai-Eliner et al. 2002). Other studies indicate that early changes in function and structure in the neurological system following stress contributes to the susceptibility to febrile convulsions, afebrile seizures, and epilepsy (Forsgren et al. 2005; Greenwood et al. 1998; Lilienfeld and Pasamancick 1955; 
Ottman 1992; Scher 2003; Weinstock 2001). A recent animal study indicated that rats have a higher risk of seizures when exposed to stress in prenatal life, in particular during the latter half of pregnancy (Edwards et al. 2002). As far as we know, no data on humans have been published.

We hypothesized that stress hormones in pregnant mothers could cross the placenta and enter the fetal circulation (Gitau et al. 1998), which may program brain development in fetus (Seckl 2004). In a nationwide cohort with almost complete follow up, we examined the association between prenatal stress following bereavement and the risk of febrile seizures in children. We expected that the association is stronger if the mothers experienced bereavement due to unexpected death than other causes of death (Hansen et al. 2000; Li et al. 2003; Sweeting and Gilhooly 1990). We also assumed that loss of a child was more severe than loss of other relatives (Skodol and Shrout 1989), and that the effect of prenatal stress on the risk of febrile seizures varied with timing of bereavement (Seckl 2004).

\section{Methods}

This is a population-based cohort study based on data from nationwide registers, which has been described elsewhere (Li et al. 2008). In short, we used data from the Danish civil registration system (CRS; Pedersen et al. 2006) to identify all singletons born in Denmark between January 1, 1978, and December 31, 2002, $(N=1,431,175)$ and their next of kin (mother, father, siblings, mother's siblings, and mother's parents). The date of conception was estimated by the date of birth minus gestational age, and the prenatal period included from 12 months before conception until the birth of the child. We categorized children as exposed to bereavement during prenatal life if their mothers lost a child, husband, sibling, or a parent during the prenatal period. The remaining children were included into the unexposed cohort. Cohort members were followed from 3 months of age until the first diagnosis of febrile seizures, death, emigration, until they reached 5 years of age, or 31 December 2006, whichever came first.

\section{Febrile Seizures}

Information on febrile seizures for both index children and mothers was obtained from the National Hospital Register (Andersen et al. 1999), which holds information on all discharges from Danish hospitals since 1977; outpatients have been included in the register since 1995. Diagnostic information is based on the Danish version of the International Classification of Diseases, eighth revision (ICD-8) from 1977 to 1993, and the International Classification of Diseases, tenth revision (ICD-10) from 1994 onwards. All treatments in Danish hospitals are free of charge for all residents. Cohort members were classified with febrile seizures case if they had been hospitalized or had been in outpatient care with a febrile seizures diagnosis (ICD 8 code 780.21 or ICD 10 codes R56.0) between 3 months and 5 years of age and they had no history of epilepsy (ICD 8 codes 345 , ICD 10 codes G40-G41, R56.8), no history of intracerebral infections (ICD 8 codes 320-323, ICD 10 codes G00-G09), and no history of cerebral palsy (IDC 8 codes 343-344, ICD 10 codes G80-83).

\section{Covariates}

Perinatal factors (gestational age, birth weight, sibling order, Apgar score at $5 \mathrm{~min}$ ) were retrieved from Medical Birth Register, which was established in 1968 and has been computerized since 1973 (Knudsen and Olsen 1998). It holds data on all live births and stillbirths in Denmark, including characteristics of mother and child and data on pregnancy and delivery. Socio-demographic factors (paternal age, maternal age, residential place, maternal education, maternal income, and maternal cohabitation status) were obtained from the Integrated Database for Longitudinal Labour Market Research, which contains longitudinal information on demographic variables and socioeconomic data from 1980 onwards (Denmark Statistics 1991).

\section{Statistical Analysis}

We used Cox regression model (SAS PROC PHREG procedure, version 9.1) to estimate hazard ratios (HRs). The option of COVSANDWICH (AGGREGATE) was applied by using maternal CPR as ID in the model to treat all siblings from the same mother in a matched set, in order to take into account the common familial factors, such as genetic predisposition and family environment. To examine whether the associations depended on type of bereavement, we first categorized the exposure into two groups by the relation of mothers to the deceased: loss of a child and loss of other relatives. We further categorized the exposure by the causes of death into two groups: unexpected death (unexpected causes, ICD8 codes 7950-7959, ICD 10 codes R95-R97, motor vehicle accidents, ICD8 codes 8100-8230, ICD10 codes V01-V89, suicide, ICD8 codes 950-959, ICD10 codes X60-X84, other accidents and violence, ICD8 codes 800-807, 825-949, 960-999, ICD10 codes V90-V99, W00-X59, X85-Y89), and death by other causes. The exposure window was divided into five periods (12-7 months before conception, 6-0 months before conception, first trimester, second trimester, and third trimester) to examine whether exposure at different time periods in fetal development have different effects on the brain with regard to the risk of febrile seizures. 
We adjusted for the following factors that have been suggested to be potentially associated with both prenatal stress and febrile seizures (Cassano et al. 1990; Greenwood et al. 1998; Nelson and Ellenberg 1990; Vestergaard et al. 2002, 2005): gender (male, female), birth year (1978-1986, 1987-1995, 1996+), gestational age (less than 37 weeks, $37+$ weeks), Apgar score at 5 min (0-7, 8-9, 10, unknown), sib order $(1,2,3,4+$, unknown), paternal age group $(<29$, 29-33, 34 years and over), maternal age group ( $<27,27-30$, 31 years and over), maternal residential place (Capital city of Copenhagen, cities with over 100,000 inhabitants, other places), maternal education (0-9, 10-11, 12+ years), maternal income (lowest quartile, second quartile, third quartile, highest quartile in the calendar year), parental cohabitation status (yes, no). In sub-analyses, we performed separate analyses in boys and girls, and in children with or without optimal birth characteristics (birth weight $>2,500 \mathrm{~g}$, gestational age $>37$ weeks, and Apgar score of 10).

\section{Results}

Among the 1,431,175 singletons born in Denmark from 1978 to 2002, we identified 34,777 children whose mothers had experienced bereavement during pregnancy or within 1 year before gestation. These exposed children were more likely born late in the study period and less likely the first born child, compared to the unexposed children. The exposed and the unexposed groups were comparable on other baseline characteristics (Table 1).

Overall, the adjusted hazard ratio (HR) of febrile seizures in children born to bereaved mothers was 1.00 (95\% CI 0.94-1.06), compared to the unexposed children. The HR for children born to mothers who lost a child was 1.09 (95\% CI 0.96-1.25), and the HR for children born to mothers who lost other relatives was 1.02 (95\% CI 0.911.15). The risk estimates did not differ by causes of death (unexpected causes vs. other causes; Table 2).

Tables 3 presents the effects of bereavement occurred in different prenatal time periods. There were no increased relative risk for separate different periods (12-7 months before conception, 6-0 months before conception, first trimester, second trimester, and third trimester; Table 3). We also obtained similar results when we stratified on gender or whether children were born with or without optimal birth characteristics (birth weight $>2,500 \mathrm{~g}$, gestational age $>$ 37 weeks and an Apgar score of 10 at 5 min; data not shown).

\section{Discussion}

The risk of febrile seizures in children exposed to stress during prenatal life was similar to what was seen among
Table 1 Baseline characteristics of the study population [value at $n$ $(\%)]$

\begin{tabular}{|c|c|c|}
\hline Variables & $\begin{array}{l}\text { Exposed cohort } \\
(n=34,777)\end{array}$ & $\begin{array}{l}\text { Unexposed cohort } \\
(n=1,396,398)\end{array}$ \\
\hline \multicolumn{3}{|l|}{ Gender } \\
\hline Boys & $17,787(51)$ & $716,991(51)$ \\
\hline Girls & $16,990(49)$ & 679,407 (49) \\
\hline \multicolumn{3}{|l|}{ Birth year } \\
\hline 1978-1987 & $5,952(17)$ & $480,834(34)$ \\
\hline 1988-1994 & $10,742(31)$ & $424,844(30)$ \\
\hline 1995-2002 & $18,083(52)$ & $490,720(35)$ \\
\hline \multicolumn{3}{|c|}{ Apgar score at $5 \mathrm{~min}$} \\
\hline $0-7$ & $451(1)$ & $17255(1)$ \\
\hline $8-9$ & $1947(6)$ & $74279(6)$ \\
\hline 10 & $32030(92)$ & $1292205(92)$ \\
\hline Unknown & $349(1)$ & $12659(1)$ \\
\hline \multicolumn{3}{|l|}{ Sib order } \\
\hline 1 & $8,407(24)$ & $477,528(34)$ \\
\hline 2 & $7,733(22)$ & $374,850(27)$ \\
\hline 3 & $3,509(10)$ & $133,450(10)$ \\
\hline $4+$ & $1,230(3)$ & $46,435(3)$ \\
\hline Unknown & $13,898(40)$ & $364,135(26)$ \\
\hline \multicolumn{3}{|l|}{ Gestational age } \\
\hline$<37$ weeks & $2,104(5)$ & $68,950(5)$ \\
\hline$>=37$ weeks & $37,763(95)$ & $1,445,141(95)$ \\
\hline \multicolumn{3}{|c|}{ Paternal age (years) } \\
\hline$<28$ & $10,665(31)$ & $450,385(32)$ \\
\hline $29-33$ & $12,713(37)$ & $492,789(35)$ \\
\hline$>33$ & $10,812(31)$ & $432,289(31)$ \\
\hline Unknown & $587(2)$ & $20,935(2)$ \\
\hline \multicolumn{3}{|c|}{ Maternal age (years) } \\
\hline $13-26$ & $11,607(33)$ & $495,085(35)$ \\
\hline $27-30$ & $11,412(33)$ & $439,627(31)$ \\
\hline $30+$ & $11,758(33)$ & $461,682(33)$ \\
\hline \multicolumn{3}{|l|}{ Maternal age } \\
\hline $13-26$ & $12,578(32)$ & $518,103(34)$ \\
\hline $27-30$ & $13,027(33)$ & $476,824(31)$ \\
\hline$>30$ & $14,262(36)$ & $519,170(34)$ \\
\hline \multicolumn{3}{|c|}{ Maternal education } \\
\hline Primary & $14,004(40)$ & $564,841(40)$ \\
\hline Secondary & $11,443(33)$ & $416,657(30)$ \\
\hline High & $8,683(25)$ & $326,638(23)$ \\
\hline Unknown & $647(2)$ & $88,262(6)$ \\
\hline \multicolumn{3}{|l|}{ Maternal income } \\
\hline 1st quartile & $8,878(25)$ & $317,677(23)$ \\
\hline 2nd quartile & $14,533(42)$ & $513,912(37)$ \\
\hline 3rd quartile & $8,469(24)$ & $380,560(27)$ \\
\hline 4th quartile & $2,249(6)$ & $95,948(7)$ \\
\hline Unknown & $648(2)$ & $88,301(6)$ \\
\hline \multicolumn{3}{|c|}{ Maternal cohabitation status } \\
\hline Single & $14,826(43)$ & $516,828(37)$ \\
\hline
\end{tabular}


Table 1 continued

\begin{tabular}{|c|c|c|}
\hline Variables & $\begin{array}{l}\text { Exposed cohort } \\
(n=34,777)\end{array}$ & $\begin{array}{l}\text { Unexposed cohort } \\
(n=1,396,398)\end{array}$ \\
\hline Cohabitation & $19,304(56)$ & 791,308 (57) \\
\hline Unknown & $647(2)$ & $88,262(6)$ \\
\hline \multicolumn{3}{|c|}{ Maternal residence } \\
\hline Copenhagen & $8,149(23)$ & 340,398 (24) \\
\hline Cities $^{\mathrm{a}}$ & $4,148(12)$ & $158,490(11)$ \\
\hline Other & $21,833(63)$ & $809,248(58)$ \\
\hline Unknown & $647(2)$ & $88,262(6)$ \\
\hline
\end{tabular}

${ }^{a}$ Cities with over 100,000 inhabitants

the unexposed children. We consider it unlikely that prenatal severe stress have a programming effect on the risk of febrile seizures in early childhood in humans although animal studies have indicated such an association. We found no support for our hypothesis.

Most etiological studies on febrile seizures have focused on genetic factors (Berkovic and Scheffer 1998; Vestergaard et al. 2002), but the fact that risk of febrile seizures increases with deceasing birth weight and gestational age indicates an effect of early environmental factors. However, only a few prenatal environmental factors have been identified and studies often provided conflicting results (Cassano et al. 1990; Greenwood et al. 1998; Nelson and Ellenberg 1990; Vestergaard et al. 2002, 2005). For example, maternal smoking or alcohol consumption were associated with an increased risk of febrile seizure in some (Berg et al. 1995; Cassano et al. 1990; Nelson and Ellenberg 1990), but not all studies (Bethune et al. 1993; Vestergaard et al. 2005).

On the other hand, evidence from both animal and human studies suggests that prenatal exposure to stress or glucocorticoids, manifested by non-optimal intrauterine environment, may play an important role in brain development via 'fetal programming'(Drake et al. 2007). In a recent study, psychological stress associated with the World
Trade Centre attacks was associated with reduced infant head circumference at birth (Engel et al. 2005). Another study found that severe stress in mothers increased the prevalence of congenital malformations in children (Hansen et al. 2000). The long-term effects of fetal glucocorticoid exposure in humans are not well examined (Aghajafari et al. 2001). To our knowledge, our study is the first population based study to investigate the association between prenatal stress and subsequent febrile seizures risk.

We also attempted to examine a possible 'doseresponse' association with bereavement by stratification on causes of death and mother's relationship to the deceased because unexpected death and loss of a child seem to be more stressful than other types of bereavement (Hansen et al. 2000; Li et al. 2003; Sweeting and Gilhooly 1990). However, we found no evidence of a dose-response-like pattern. Although it has been suggested that stress occurred at different prenatal periods could affect the fetus differently (Drake et al. 2007), we observed no elevated risk across the periods of before conception or during three trimesters. These findings suggest that even the most severe form of prenatal stress has no substantial programming effects on the development of febrile seizures in later life.

Our study has important strengths. It is a large population-based cohort consisting of all children born in Denmark from 1978 to 2002 and we have the information on hospitalization for all these children from birth to 5 years of age. Bias due to selection of study participants and nonresponse are, therefore, an unlikely explanation for our findings. Registration of day of death in the Danish CPR register has a high validity with a completeness close to $100 \%$, making our exposure information accurate Pedersen et al. 2006). Furthermore, the validity of Febrile seizures in Danish Hospitalization Register has been shown to be high with a predictive value of $92.8 \%$ (95\% CI 88.5-95.7; Vestergaard et al. 2006). Lastly, we were able to adjust for a number of potential confounders including gender, sib order, age of mother and father, socioeconomic factors.
Table 2 Hazard ratio (HR) for febrile seizures in children whose mothers lost a relative, by mother's relation to the deceased, and cause of death

\footnotetext{
${ }^{a}$ HR adjusted for gender, age group, sib order, calendar period, maternal education, maternal income, maternal residence place, and maternal cohabitation status
}

\begin{tabular}{llll}
\hline Type of bereavement & $\begin{array}{l}\text { Cases in the exposed/ } \\
\text { cases in the unexposed }\end{array}$ & $\begin{array}{l}\text { Crude HR } \\
(95 \% \mathrm{CI})\end{array}$ & $\begin{array}{l}\text { Adjusted HR } \\
(95 \% \mathrm{CI})^{\mathrm{a}}\end{array}$ \\
\hline All loss & $1214 / 46634$ & $1.05(0.99-1.11)$ & $1.00(0.94-1.06)$ \\
$\quad$ Unexpected death & $356 / 46634$ & $1.00(0.90-1.11)$ & $1.03(0.96-1.10)$ \\
$\quad$ Other death & $858 / 46634$ & $1.07(1.00-1.14)$ & $0.95(0.85-1.05)$ \\
$\quad$ Loss of a child & $234 / 46634$ & $1.08(0.95-1.23)$ & $1.09(0.96-1.25)$ \\
$\quad$ Unexpected death & $33 / 46634$ & $1.04(0.95-1.25)$ & $1.09(0.77-1.54)$ \\
$\quad$ Other death & $201 / 46634$ & $1.09(0.74-1.47)$ & $1.12(0.97-1.31)$ \\
$\quad$ Loss of partner/spouse, & $983 / 31884$ & $1.03(0.97-1.10)$ & $1.02(0.91-1.15)$ \\
$\quad$ a parent, or a sibling & & & \\
$\quad \begin{array}{l}\text { Unexpected death } \\
\quad \text { Other death }\end{array}$ & $323 / 31884$ & $0.99(0.89-1.12)$ & $0.93(0.83-1.08)$ \\
\hline
\end{tabular}


Table 3 HR for febrile seizures in children whose mothers lost a relative, by mother's relation to the deceased and timing of loss

\begin{tabular}{llll}
\hline Exposure category & $\begin{array}{l}\text { Cases in the exposed/cases } \\
\text { in the unexposed }\end{array}$ & Crude HR (95\% CI) & Adjusted HR (95\% CI $)^{\mathrm{a}}$ \\
\hline All loss & & & \\
12-7 months before conception & $356 / 46634$ & $1.07(0.97-1.19)$ & $1.03(0.93-1.15)$ \\
1-6 months before conception & $402 / 46634$ & $1.05(0.96-1.16)$ & $1.01(0.92-1.12)$ \\
1st trimester & $140 / 46634$ & $1.08(0.91-1.27)$ & $1.02(0.86-1.20)$ \\
2nd trimester & $158 / 46634$ & $0.95(0.82-1.11)$ & $0.90(0.77-1.06)$ \\
3rd trimester & $158 / 46634$ & $1.04(0.89-1.22)$ & $0.99(0.85-1.16)$ \\
Loss of a child & & & $1.02(0.81-1.27)$ \\
12-7 months before conception & $78 / 46634$ & $0.99(0.80-1.24)$ & $1.13(0.95-1.35)$ \\
1-6 months before conception & $124 / 46634$ & $1.12(0.94-1.33)$ & $1.27(0.71-2.30)$ \\
1st trimester & $11 / 46634$ & $1.25(0.69-2.26)$ & $0.95(0.49-1.82)$ \\
2nd trimester & $9 / 46634$ & $0.95(0.49-1.82)$ & $1.32(0.75-2.33)$ \\
3rd trimester & $12 / 46634$ & $1.31(0.74-2.31)$ & $1.04(0.92-1.16)$ \\
Loss of partner/spouse, a parent, or a sibling & & $0.96(0.86-1.08)$ \\
12-7 months before conception & $280 / 31884$ & $1.10(0.98-1.24)$ & $1.00(0.84-1.19)$ \\
1-6 months before conception & $279 / 31884$ & $1.12(0.91-1.15)$ & $0.90(0.77-1.06)$ \\
1st trimester & $129 / 31884$ & $1.06(0.89-1.26)$ & $0.97(0.82-1.14)$ \\
2nd trimester & $149 / 31884$ & $0.95(0.81-1.12)$ & $1.02(0.87-1.20)$ \\
3rd trimester & $146 / 31884$ & & \\
\hline
\end{tabular}

${ }^{a}$ HR adjusted for gender, age group, sib order, calendar period, maternal education, maternal income, maternal residence place, and maternal cohabitation status

The study is limited by the fact that we had no data on glucocorticoids changes in mothers following bereavement. It is, however, not realistic to have biological measurements for such a large study population. And a large body of literature has demonstrated that bereavement is one of the most stressful life events (Holmes and Rahe 1967; Osterweis et al. 1984), followed by a substantial physiological response in the neuroendocrine systems. Those changes include altered HPA axis, hypothalamic dysregulation, and excessive secretion of $\mathrm{CRH}$ and cortisol (Goodkin et al. 2001). In conclusion, we found no evidence for an increased risk of febrile seizures in children born to mothers who experienced bereavement by death of a close family member during the prenatal period.

Acknowledgments The study was supported by the Danish Medical Research Council (project no. 271-05-0616 and project no. 271-070437), NordForst (project no. 070331), and Gigtforeningen.

Open Access This article is distributed under the terms of the Creative Commons Attribution Noncommercial License which permits any noncommercial use, distribution, and reproduction in any medium, provided the original author(s) and source are credited.

\section{References}

Aghajafari, F., Murphy, K., Willan, A., Ohlsson, A., Amankwah, K., Matthews, S., et al. (2001). Multiple courses of antenatal corticosteroids: A systematic review and meta-analysis. American Journal of Obstetrics and Gynecology, 185, 1073-1080. doi:10.1067/mob.2001.117635.

Andersen, T. F., Madsen, M., Jorgensen, J., Mellemkjoer, L., \& Olsen, J. H. (1999). The Danish national hospital register. A valuable source of data for modern health sciences. Danish Medical Bulletin, 46, 263-268.

Barrot, M., Abrous, D. N., Marinelli, M., Rouge-Pont, F., Le, M. M., \& Piazza, P. V. (2001). Influence of glucocorticoids on dopaminergic transmission in the rat dorsolateral striatum. The European Journal of Neuroscience, 13, 812-818. doi:10.1046/ j.1460-9568.2001.01434.x.

Berg, A. T., Shinnar, S., Shapiro, E. D., Salomon, M. E., Crain, E. F., \& Hauser, W. A. (1995). Risk factors for a first febrile seizure: A matched case-control study. Epilepsia, 36, 334-341. doi:10.1111/ j.1528-1157.1995.tb01006.x.

Berkovic, S. F., \& Scheffer, I. E. (1998). Febrile seizures: Genetics and relationship to other epilepsy syndromes. Current Opinion in Neurology, 11, 129-134. doi:10.1097/00019052-199804000-00009.

Bethune, P., Gordon, K., Dooley, J., Camfield, C., \& Camfield, P. (1993). Which child will have a febrile seizure? American Journal of Diseases of Children, 147, 35-39.

Brunson, K. L., Chen, Y., Vishai-Eliner, S., \& Baram, T. Z. (2003). Stress and the developing hippocampus: A double-edged sword? Molecular Neurobiology, 27, 121-136. doi:10.1385/MN:27:2:121.

Cassano, P. A., Koepsell, T. D., \& Farewell, J. R. (1990). Risk of febrile seizures in childhood in relation to prenatal maternal cigarette smoking and alcohol intake. American Journal of Epidemiology, 132, 462-473.

Denmark Statistics. (1991). IDA-an intergrated database for labor market research (In Danish). (http://www.dst.dk/) [under IDA (Intergrated Database for Arbejdsmarkedsforskning)].

Drake, A. J., Tang, J. I., \& Nyirenda, M. J. (2007). Mechanisms underlying the role of glucocorticoids in the early life 
programming of adult disease. Clinical Science (London, England), 113, 219-232. doi:10.1042/CS20070107.

Edwards, H. E., Dortok, D., Tam, J., Won, D., \& Burnham, W. M. (2002). Prenatal stress alters seizure thresholds and the development of kindled seizures in infant and adult rats. Hormones and Behavior, 42, 437-447. doi:10.1006/hbeh.2002.1839.

Engel, S. M., Berkowitz, G. S., Wolff, M. S., \& Yehuda, R. (2005). Psychological trauma associated with the world trade center attacks and its effect on pregnancy outcome. Paediatric and Perinatal Epidemiology, 19, 334-341. doi:10.1111/j.1365-3016. 2005.00676.x.

Forsgren, L., Beghi, E., Oun, A., \& Sillanpaa, M. (2005). The epidemiology of epilepsy in Europe-a systematic review. European Journal of Neurology, 12, 245-253. doi:10.1111/j.14681331.2004.00992.x.

Forsgren, L., Sidenvall, R., Blomquist, H. K., Heijbel, J., \& Nystrom, L. (1990). An incident case-referent study of febrile convulsions in children: Genetical and social aspects. Neuropediatrics, 21, 153-159. doi:10.1055/s-2008-1071484.

Gitau, R., Cameron, A., Fisk, N. M., \& Glover, V. (1998). Fetal exposure to maternal cortisol. Lancet, 352, 707-708. doi: 10.1016/S0140-6736(05)60824-0.

Goodkin, K., Baldewicz, T. T., Blaney, N. T., Asthana, D., Kumar, M., Shapshak, P., et al. (2001). Physiological effects of bereavement and bereavement support group interventions. In M. S. Stroebe, R. O. Hansson, W. Stroebe, \& H. Schut (Eds.), Handbook of bereavement research (pp. 671-704). Washington, DC: American Psychological association.

Greenwood, R., Golding, J., Ross, E., \& Verity, C. (1998). Prenatal and perinatal antecedents of febrile convulsions and afebrile seizures: Data from a national cohort study. Paediatric and Perinatal Epidemiology, 12, 76-95. doi:10.1046/j.1365-3016. 1998.0120s1076.x.

Hansen, D., Lou, H. C., \& Olsen, J. (2000). Serious life events and congenital malformations: A national study with complete follow-up. Lancet, 356, 875-880. doi:10.1016/S0140-6736 (00)02676-3.

Hauser, W. A. (1994). The prevalence and incidence of convulsive disorders in children. Epilepsia, 35, S1-S6. doi:10.1111/ j.1528-1157.1994.tb05932.x.

Holmes, T. H., \& Rahe, R. H. (1967). The social readjustment rating scale. Journal of Psychosomatic Research, 11, 213-218. doi: 10.1016/0022-3999(67)90010-4

Kapoor, A., Dunn, E., Kostaki, A., Andrews, M. H., \& Matthews, S. G. (2006). Fetal programming of hypothalamo-pituitary-adrenal function: Prenatal stress and glucocorticoids. The Journal of Physiology, 572, 31-44.

Knudsen, L. B., \& Olsen, J. (1998). The Danish medical birth registry. Danish Medical Bulletin, 45, 320-323.

Li, J., Precht, D. H., Mortensen, P. B., \& Olsen, J. (2003). Mortality in parents after death of a child in Denmark: A nationwide followup study. Lancet, 361, 363-367. doi:10.1016/S0140-6736 (03) $12387-2$.

Li, J., Vestergaard, M., Obel, C., Precht, D. H., Christensen, J., Lu, M., et al. (2008). Prenatal stress and epilepsy in later life: A nationwide follow-up study in Denmark. Epilepsy Research, 81, 52-57.

Lilienfeld, A. M., \& Pasamancick, B. (1955). The association of maternal and fetal factors with the development of cerebral palsy and epilepsy. American Journal of Obstetrics and Gynecology, 70, 93-101.
Nelson, K. B., \& Ellenberg, J. H. (1990). Prenatal and perinatal antecedents of febrile seizures. Annals of Neurology, 27, 127131. doi:10.1002/ana.410270206.

Osterweis, M., Solomon, F., \& Green, M. (1984). Bereavement: Reactions, consequences, and care. Washington, DC: National Academy Press.

Ottman, R. (1992). Genetic and developmental influences on susceptibility to epilepsy: Evidence from twins. Paediatric and Perinatal Epidemiology, 6, 265-272. doi:10.1111/j.1365-3016. 1992.tb00766.x.

Pedersen, C. B., Gotzsche, H., Moller, J. O., \& Mortensen, P. B. (2006). The Danish civil registration system. A cohort of eight million persons. Danish Medical Bulletin, 53, 441-449.

Scher, M. S. (2003). Prenatal contributions to epilepsy: Lessons from the bedside. Epileptic Disorders, 5, 77-91.

Seckl, J. (2004). Prenatal glucocorticoids and long-term programming. European Journal of Endocrinology, 151, U49-U62. doi: 10.1530/eje.0.151U049.

Seckl, J. R., \& Holmes, M. C. (2007). Mechanisms of disease: Glucocorticoids, their placental metabolism and fetal 'programming' of adult pathophysiology. Nature Clinical Practice Endocrinology \& Metabolism, 3, 479-488. doi:10.1038/ncpendmet0515.

Skodol, A. E., \& Shrout, P. E. (1989). Use of DSM-III axis IV in clinical practice: Rating etiologically significant stressors. The American Journal of Psychiatry, 146, 61-66.

Sweeting, H. N., \& Gilhooly, M. L. (1990). Anticipatory grief: A review. Social Science and Medicine, 30, 1073-1080. doi: 10.1016/0277-9536(90)90293-2.

Van den Bergh, B. R., Mulder, E. J., Mennes, M., \& Glover, V. (2005). Antenatal maternal anxiety and stress and the neurobehavioral development of the fetus and child: Links and possible mechanisms. A review. Neuroscience and Biobehavioral Reviews, 29, 237-258. doi:10.1016/j.neubiorev.2004.10.007.

Vestergaard, M., Basso, O., Henriksen, T. B., Ostergaard, J. R., \& Olsen, J. (2002). Risk factors for febrile convulsions. Epidemiology (Cambridge, Mass.), 13, 282-287. doi:10.1097/00001648200205000-00008.

Vestergaard, M., Obel, C., Henriksen, T. B., Christensen, J., Madsen, K. M., Ostergaard, J. R., et al. (2006). The Danish national hospital register is a valuable study base for epidemiologic research in febrile seizures. Journal of Clinical Epidemiology, 59, 61-66. doi:10.1016/j.jclinepi.2005.05.008.

Vestergaard, M., Wisborg, K., Henriksen, T. B., Secher, N. J., Ostergaard, J. R., \& Olsen, J. (2005). Prenatal exposure to cigarettes, alcohol, and coffee and the risk for febrile seizures. Pediatrics, 116, 1089-1094. doi:10.1542/peds.2004-2210.

Vishai-Eliner, S., Brunson, K. L., Sandman, C. A., \& Baram, T. Z. (2002). Stressed-out, or in (utero)? Trends in Neurosciences, 25, $518-524$.

Wadhwa, P. D. (2005). Psychoneuroendocrine processes in human pregnancy influence fetal development and health. Psychoneuroendocrinology, 30, 724-743.

Weinstock, M. (2001). Alterations induced by gestational stress in brain morphology and behaviour of the offspring. Progress in Neurobiology, 65, 427-451.

Weinstock, M. (2005). The potential influence of maternal stress hormones on development and mental health of the offspring. Brain, Behavior, and Immunity, 19, 296-308.

Welberg, L. A., \& Seckl, J. R. (2001). Prenatal stress, glucocorticoids and the programming of the brain. Journal of Neuroendocrinology, 13, 113-128. 